\title{
Uncertainty and variability in atmospheric formation of PFCAs from fluorotelomer precursors
}

\author{
Colin P. Thackray ${ }^{1}$ and Noelle E. Selin ${ }^{1,2}$ \\ ${ }^{1}$ Department of Earth, Atmospheric and Planetary Sciences, Massachusetts Institute of Technology, \\ 77 Massachusetts Avenue, Cambridge, MA 02139, USA \\ ${ }^{2}$ Institute for Data, Systems and Society, Massachusetts Institute of Technology, 77 Massachusetts Avenue, \\ Cambridge, MA 02139, USA \\ Correspondence to: Colin P. Thackray (thackray@mit.edu)
}

Received: 26 July 2016 - Discussion started: 26 August 2016

Revised: 31 December 2016 - Accepted: 26 February 2017 - Published: 6 April 2017

\begin{abstract}
Perfluoroalkyl carboxylic acids (PFCAs) are environmental contaminants that are highly persistent, bioaccumulative, and have been detected along with their atmospheric precursors far from emissions sources. The importance of precursor emissions as an indirect source of PFCAs to the environment is uncertain. Modeling studies have used degradation mechanisms of differing complexities to estimate the atmospheric production of PFCAs, and these differing mechanisms lead to quantitatively different yields of PFCAs under differing atmospheric conditions. We evaluate PFCA formation with the most complete degradation mechanism to date, to our knowledge, using a box model analysis to simulate the atmospheric chemical fate of fluorotelomer precursors to long-chain PFCAs. In particular, we examine the variability in PFCA formation in different chemical environments, and estimate the uncertainty in PFCA formation due to reaction rate constants.

We calculate long-chain PFCA formation theoretical maximum yields for the degradation of fluorotelomer precursor species at a representative sample of atmospheric conditions from a three-dimensional chemical transport model, and estimate uncertainties in such calculations for urban, ocean, and Arctic conditions using polynomial chaos methods. We find that atmospheric conditions farther from pollution sources have both higher capacities to form long-chain PFCAs and higher uncertainties in those capacities.

Our calculations of theoretical maximum yields indicate that under typical Northern Hemisphere conditions, less than $10 \%$ of emitted precursor may reach long-chain PFCA end products. This results in a possible upper bound of 2-
\end{abstract}

50 tyear $^{-1}$ of long-chain PFCA (depending on quantity of emitted precursor) produced in the atmosphere via degradation of fluorotelomer products. However, transport to highyield areas could result in higher yields. While the atmosphere is a potentially growing source of long-chain PFCAs in the Arctic, oceanic transport and interactions between the atmosphere and ocean may be relatively more important pathways to the Arctic for long-chain PFCAs.

\section{Introduction}

Perfluoroalkyl carboxylic acids (PFCAs) are environmental contaminants that are highly persistent, bio-accumulative (Martin et al., 2003a, b; Conder et al., 2008), and have been detected along with their atmospheric precursors far from emissions sources (Young et al., 2007; Shoeib et al., 2006; Stock et al., 2007) in snow (Xie et al., 2015), precipitation (Scott et al., 2006), and biota (Houde et al., 2006). Of particular environmental interest are the long-chain PFCA (lcPFCA, PFCAs of chain length greater than 7) homologues such as PFOA (8-carbon chain), due to the increased bioaccumulation with chain length (Martin et al., 2003a, b; Conder et al., 2008). PFCAs and their salts are directly emitted to the environment and can be transported long distances via the ocean, having important consequences for remote aquatic biota. While lcPFCAs are not regulated internationally, reducing ICPFCA emissions has been the focus of some national policy actions due to their detrimental health effects (Vierke et al., 2012), and as a result, direct emissions have been decreas- 
ing globally. At the same time, emissions of atmospheric precursors of PFCAs are rising (Wang et al., 2014a), leading to an increasing indirect source of PFCAs to the environment. These precursors, including fluorotelomer alcohols (FTOHs), react with atmospheric photochemical species (Ellis et al., 2003) in a multi-stage process to form PFCAs (Young and Mabury, 2010). However, the importance of precursor emissions as an indirect source of lcPFCAs to the environment is uncertain. Estimated yields of PFCAs from precursors can vary based on differences in the formation mechanism assumed, quantitative uncertainty in reaction rate constants, and ambient concentrations of other atmospheric species. Here, we use a box model analysis to quantitatively estimate potential upper-limit atmospheric yields of PFCAs, incorporating uncertainty in the precursor degradation mechanism and variability of atmospheric PFCA formation due to photochemical background conditions.

Previous studies have estimated yields of lcPFCAs from the degradation of FTOHs in the atmosphere (Yarwood et al., 2007; Wallington et al., 2006). However, studies have indicated that other emitted atmospheric precursors exist in the form of other fluorotelomer compounds, perfluoroalkyl sulfonamides (FOSAs), and perfluoroalkyl sulfonamidoethanols (FOSEs) (Young and Mabury, 2010; Wang et al., 2014a, b; Young et al., 2008; Butt et al., 2009). Rate coefficients for the reactions in the PFCA formation mechanism are uncertain, affecting estimated yields. The atmospheric formation of PFCAs depends on reactions of fluorinated intermediates (Waterland and Dobbs, 2007; Chiappero et al., 2006) with commonly studied photochemical species, such as $\mathrm{HO}_{x}$ and $\mathrm{NO}_{x}$ species, as well as ultraviolet light. These species vary greatly over different environments in the atmosphere, affecting the quantity of lcPFCA produced.

Modeling studies have used degradation mechanisms of differing complexities to estimate the atmospheric production of PFCAs, and these differing mechanisms lead to quantitatively different yields of lcPFCAs under differing atmospheric conditions. Wallington et al. (2006) simulated the atmospheric degradation of $8: 2$ FTOHs using the IMPACT atmospheric chemistry model, finding that PFOA yields ranged from 1 to $10 \%$ depending on location and time. Yarwood et al. (2007) used a higher-resolution atmospheric chemistry model over North America to estimate that degradation yielded approximately $6 \%$ PFOA on average, and much less than $1 \%$ PFNA. Schenker et al. (2007), using a global-scale multispecies mass-balance model with simplified chemistry, found that precursor transport and degradation could contribute to perfluorocarboxylates observed in the Arctic, and that rate constant uncertainty was an important contributor to uncertainty in their results (Schenker et al., 2007).

In our work, we evaluate PFCA formation with the most complete degradation mechanism to date, to our knowledge, including the reactions presented in the studies of Wallington et al. (2006) and Yarwood et al. (2007), and the review of Young and Mabury (2010). Our goal in this work is to ex- amine the variability in PFCA formation in different chemical environments, and estimate the uncertainty in PFCA formation due to reaction rate constants. We use a box model analysis to simulate the atmospheric chemical fate of fluorotelomer aldehyde (FTAL), a common early product in the degradation of many of the different precursor species, including FTOHs. We quantitatively estimate the influence of uncertainty in rate coefficients for calculations of PFCA yields using polynomial chaos methods, which have been used previously in the context of chemical reaction mechanisms (Phenix et al., 1998) and atmospheric chemistry modeling in particular (Cheng and Sandu, 2009; Thackray et al., 2015). We further examine the influence of different atmospheric chemical conditions on upper-limit PFCA formation based on output from a three-dimensional chemical transport model. We conclude by estimating potential upper limits for atmospherically formed PFCAs from emitted precursors, and compare our yield results to observed atmospherically formed PFCAs.

\section{Methods}

We use a box model representation of the gas-phase chemical reactions that lead to atmospheric PFCA formation to calculate yields per unit precursor species. We calculate yields of PFOA (8 Carbons) and PFNA (9 Carbons) from the degradation of $8: 2$ fluorotelomer precursors. We use prescribed concentrations of photochemical species from data sources described below. To quantify an upper limit of possible atmospheric PFCA formation, we calculate yields of PFOA and PFNA in the absence of non-chemical loss processes, such as sorption to atmospheric particulate matter or removal by wet or dry deposition. Thus, our calculations represent an upper limit of the PFCA formation capacity of the atmosphere at given photochemical conditions. We use the LSODE solver implemented in the "scipy" package of Python to solve the system of differential equations defined by this chemistry.

\subsection{Mechanism and box model}

In our box model, we use a precursor degradation mechanism which builds on the work of previous modeling efforts (Wallington et al., 2006; Yarwood et al., 2007) and includes reactions from recent literature (Young and Mabury, 2010). The chemical reactions included are listed in the Appendix, and depicted in Fig. 1. The mechanism defines the degradation of fluorotelomer aldehyde, which we use as a generic precursor as it is the first degradation product of emitted volatile fluorotelomer compounds such as FTOHs and FTiodides. This FT-aldehyde can be oxidized by $\mathrm{OH}$ or photolyzed to form peroxy or acylperoxy radicals. These radicals, in turn, react with $\mathrm{NO}, \mathrm{NO}_{2}, \mathrm{RO}_{2}$, and $\mathrm{HO}_{2}$ to form stable intermediates. These stable intermediates can again be radicalized by further reaction with $\mathrm{OH}$ and ultraviolet light, 


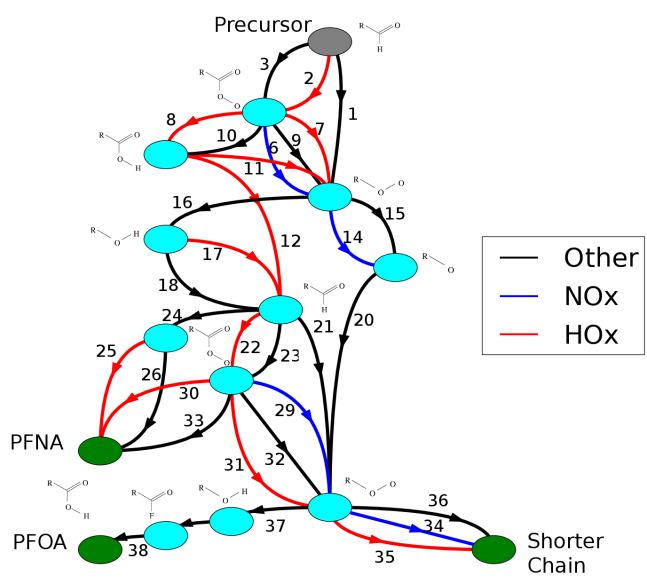

Figure 1. Diagram of reaction mechanism used in box model. Each line represents a reaction, with color of the line indicating the photochemical family of the non-fluorinated reactant. Numbers correspond to specific reactions listed in the Appendix.

with more analogous radical reactions leading to either stable PFCAs or shorter-chain intermediates. Reaction products which have chain lengths shorter than PFOA are neglected in our calculations.

We use a box model of the PFCA formation chemistry to calculate yields of PFOA and PFNA from precursor species. The single-box model simulates the chemical reactions discussed above, treating the concentrations of $\mathrm{HO}_{x}, \mathrm{NO}_{x}, \mathrm{Cl}$, and $\mathrm{RO}_{2}$ as constant and neglecting non-chemical loss processes such as wet and dry deposition. Simulations begin with a unit of precursor species and are carried out until all of the initial precursor has reached one of the reaction endpoints (PFNA, PFOA, or shorter-chain PFCAs). The yield of each end species is defined as the fraction of the initial precursor that forms that species.

\subsection{Variability of PFCA formation}

To quantify the variability of PFCA formation capacity due to variations in the atmospheric chemical background of the Northern Hemisphere, we use photochemical species concentration output from the chemical transport model GEOSChem (Bey et al., 2001). We use concentrations of $\mathrm{OH}, \mathrm{HO}_{2}$, $\mathrm{NO}$, and $\mathrm{NO}_{2}$ and temperature output from a GEOS-Chem version 9.01 .02 full chemistry simulation of the years 2006 and 2007 after a 1 year spin-up.

We calculate $\mathrm{RO}_{2}$ concentrations based on concentrations of methane, ethane, and propane from the GEOS-Chem simulation and a pseudo-steady-state approximation:

$\left[\mathrm{RO}_{2}\right] \approx$

$\frac{\left[\mathrm{CH}_{4}\right][\mathrm{OH}] k_{\mathrm{CH}_{4}+\mathrm{OH}}+\left[\mathrm{C}_{2} \mathrm{H}_{6}\right][\mathrm{OH}] k_{\mathrm{C}_{2} \mathrm{H}_{6}+\mathrm{OH}}+\left[\mathrm{C}_{3} \mathrm{H}_{8}\right][\mathrm{OH}] k_{\mathrm{C}_{3} \mathrm{H}_{8}+\mathrm{OH}}}{[\mathrm{NO}] k_{\mathrm{NO}+\mathrm{RO}_{2}}+\left[\mathrm{HO}_{2}\right] k_{\mathrm{HO}_{2}}+\mathrm{RO}_{2}}$.

Available photons for photolysis reactions were calculated based on a scaling by the position of the sun as a func-
Table 1. Case environment conditions. Photochemical concentrations are measured per cubic centimeter $\left(\mathrm{cm}^{-3}\right)$, temperatures in Kelvin (K).

\begin{tabular}{lrrr}
\hline & Urban & Ocean & Arctic \\
\hline $\mathrm{NO}$ & $2 \times 10^{10}$ & $1.7 \times 10^{7}$ & $1 \times 10^{8}$ \\
$\mathrm{OH}$ & $2 \times 10^{7}$ & $5.4 \times 10^{6}$ & $1.6 \times 10^{7}$ \\
$\mathrm{NO}_{2}$ & $2 \times 10^{11}$ & $5 \times 10^{7}$ & $1 \times 10^{8}$ \\
$\mathrm{HO}_{2}$ & $9 \times 10^{6}$ & $1 \times 10^{8}$ & $3.7 \times 10^{5}$ \\
$\mathrm{RO}_{2}$ & $8 \times 10^{6}$ & $1.6 \times 10^{9}$ & $2.2 \times 10^{8}$ \\
$h v$ & $9.4 \times 10^{14}$ & $9.76 \times 10^{14}$ & $1 \times 10^{15}$ \\
Temperature & 299 & 299 & 265 \\
\hline
\end{tabular}

tion of latitude and time of year and an assumption of clear sky conditions (Russell, 2015), and a peak actinic flux of $1 \times 10^{15}$ photons $\mathrm{cm}^{-2} \mathrm{~s}^{-1}$ at $0^{\circ}$ solar zenith angle (Seinfeld and Pandis, 2006). We use daily GEOS-Chem output concentrations from winter (January) and summer (July) of 2007 as a representative sample of the variability of atmospheric conditions in the Northern Hemisphere.

For the photochemical conditions corresponding with each surface grid box and time of the GEOS-Chem output, we perform a box model run to calculate yields and formation times of PFOA and PFNA. This results in 1656 chemical environments for each of the summer and winter conditions.

\subsection{Uncertainty propagation}

We calculate the parametric uncertainty in yields and formation times for PFCA formation in three case environments. We use conditions chosen from the above GEOS-Chem output data set representing three distinct photochemical environments as representative test cases. We have selected one each of urban, Arctic, and ocean environments for their distinctive PFCA formation behaviors. The photochemical concentrations of each environment are detailed in Table 1. The urban environment is located over urban China, and is characterized by high $\mathrm{NO}_{x}$ concentrations. The ocean environment, in contrast, is located over the equatorial Pacific Ocean and is characterized by very low $\mathrm{NO}_{x}$ concentrations. The environment illustrative of Arctic PFCA formation is located over Greenland, and is much colder and has a moderate level of $\mathrm{NO}_{x}$.

We use polynomial chaos (PC) methods to propagate uncertainty from rate constants to yields calculated by the box model. PC methods create a polynomial expansion representation of the model to propagate uncertainty in inputs to the outputs at low computational cost while being able to represent non-linear responses of outputs to model input parameters, as well as interactions between input parameters (Thackray et al., 2015; Lucas and Prinn, 2005; Cheng and Sandu, 2009). The PC-based estimator uses orthogonal polynomials to approximate GEOS-Chem model output as a function of model inputs. The polynomial expansion of the 
model output to be estimated takes the form

$$
\begin{aligned}
\eta(\zeta) & =\alpha_{0}+\sum_{j=1}^{d} \sum_{k=1}^{M} \alpha_{j, k} H_{j}\left(\zeta_{k}\right) \\
& +\sum_{k=1}^{M-1} \sum_{l=k+1}^{M} \beta_{k, l} H_{1}\left(\zeta_{k}\right) H_{1}\left(\zeta_{l}\right)+\ldots \\
& +\operatorname{Order}(d \geq O>2),
\end{aligned}
$$

where the estimator $\eta$ of degree $d$ is a function of the polynomials $H_{j}$ of order $j$, the $M$ variables $\zeta_{k}$ represent model inputs, the expansion coefficients $\alpha_{j, k}$ and $\beta_{k, l}$, and higher order coefficients. Not shown in the equation are cross terms of degree $>2$, which include the product of up to $d$ Hermite polynomials of different variables, analogous to the second order cross terms shown. In this study, we truncate the polynomial after third order. To obtain the expansion coefficients, one model run at a unique set of inputs is performed for each term in the equation (Tatang et al., 1997). The set of inputs for the model runs for each degree's terms are the values corresponding to the roots of the next degree's polynomials. The outputs of these model runs and the corresponding sets of input values are used to set up a system of equations to solve for the expansion coefficients (Lucas and Prinn, 2005). We use the polynomial estimator to directly infer properties of the uncertainty distribution of model output (in this case theoretical maximum fractional yields of PFOA and PFNA) without relying on Monte Carlo methods, which is accomplished using the analytical forms of the mean and variance from the polynomial coefficients (Lucas and Prinn, 2005). We also calculate the portion of the total output variance contributed by each rate constant using the expansion coefficients (Lucas and Prinn, 2005; Cheng and Sandu, 2009). We carry out a second-order expansion in the 40 uncertain reaction rate constants to calculate uncertainty distributions of PFOA and PFNA yields and attribute the importance of each reaction rate constant to the resulting parametric uncertainty.

\subsection{Environment categorization}

In order to categorize the differences in photochemical environments, we use the DBSCAN clustering algorithm (Ester et al., 1996) to find clusters in summer average $\mathrm{OH}-\mathrm{HO}_{2}-$ NO concentration space. These three species were chosen because they are the most common non-fluorinated reactants in the modeled chemistry, and because they led to the delineation of the observed behavior in yield-time space apparent by visual inspection (see Sect. 3.4). The DBSCAN algorithm is density-based, clustering based on the proximity of nearest neighbors in the chosen parameter space. The algorithm requires a priori values for its two parameters, $\varepsilon$, which roughly describes the size of the "neighborhood" around a datum, and $N_{\varepsilon}$, the number of other data that must be within that neighborhood to be considered a cluster. The clustering is relatively insensitive to choice of $N_{\varepsilon}$ (Ester et al., 1996), but the number of clusters found in the data set depends on the value of $\varepsilon$ chosen. We choose an $N_{\varepsilon}$ value of 10 and the $\varepsilon$ value (0.3) that gives the smallest number of clusters $>1$ for simplicity in categorization. This results in two major clusters accounting for $>85 \%$ of the data, with the remaining data unclustered.

\section{Results}

We calculate the variability in PFOA and PFNA theoretical maximum yields for summer and winter Northern Hemisphere conditions, and quantify the parametric uncertainty in these theoretical yields for three representative test cases. We also investigate the distinct chemical regimes in the formation of PFNA in different regions of the atmosphere under average summer conditions.

\subsection{Variability in yields due to photochemical environment}

Figure 2 shows histograms of theoretical maximum yields of PFOA and PFNA for each of the photochemical environments from GEOS-Chem output. Each count in the histogram corresponds to a calculation of yields carried out at the conditions from a single day and Northern Hemisphere grid-box (latitude-longitude location) from the GEOS-Chem output. For PFOA during the summer, the majority of photochemical environments result in yields of between 1 and $10 \%$, with approximately a quarter of the environments yielding $<1 \%$ and a third of environments yielding between 10 and $30 \%$. During the winter, the peak of PFOA yields remains between $1-10 \%$ but many more environments yield $<1 \%$ and fewer yield $>10 \%$ compared to during the summer.

PFNA, on the other hand, sees a peak of less than $1 \%$ during the summer, but shows a third of its environments between 1 and $10 \%$, with a small fraction of environments leading to yields higher than $80 \%$. During the winter, PFNA formation skews toward very low yields of $<0.1 \%$. The long tails of PFNA formation environments are discussed further in Sect. 3.4. Previous work (Yarwood et al., 2007) quantified yields of PFOA and PFNA over the United States, but the extreme capacities to yield lcPFCAs in remote low- $\mathrm{NO}_{x}$ environments have been previously unquantified.

\subsection{Uncertainty in yields due to rate constant uncertainty}

Figure 3 shows uncertainty in PFOA and PFNA yields due to uncertainty in the rate constants in the degradation mechanism. For both species, yields are negligible under the high$\mathrm{NO}_{x}$ urban conditions, in agreement with previous work focused on North America (Yarwood et al., 2007). Under oceanic conditions far from $\mathrm{NO}_{x}$ sources, the PFOA yield is approximately $20 \%$, with an uncertainty range of approx- 

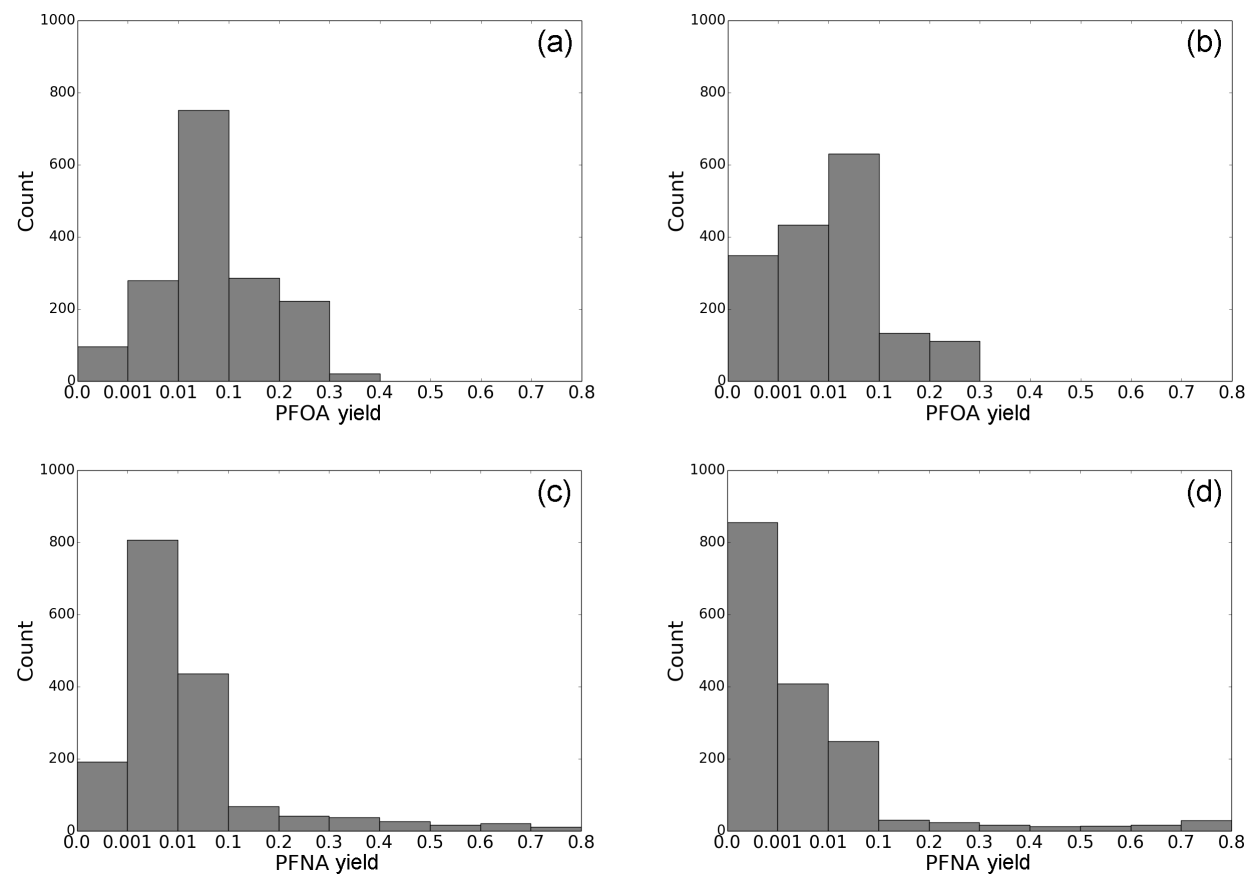

Figure 2. Histograms of variability in PFOA (a, b) and PFNA (c, d) theoretical maximum yields for both summer (a, c) and winter (b, d) conditions. Each count corresponds to a GEOS-Chem grid box's output photochemical environment.
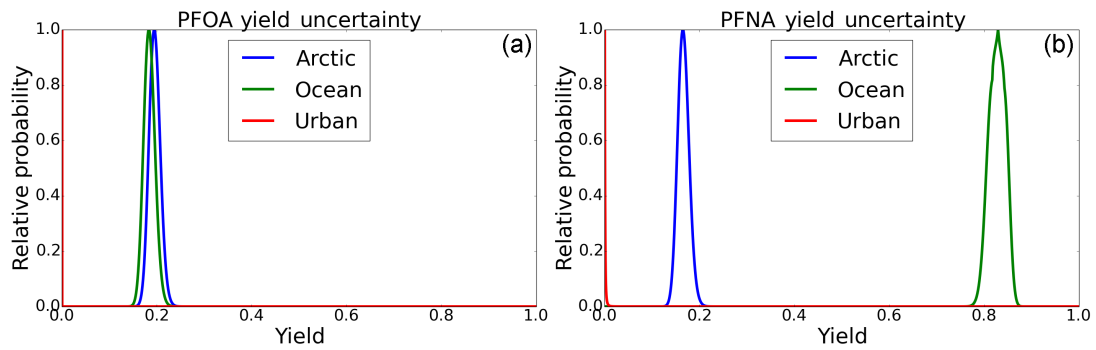

Figure 3. Uncertainty distributions of PFOA (a) and PFNA (b) yields for urban, ocean, and Arctic conditions. In both cases, urban yields are much less than $1 \%$.

imately $3 \%$, and the PFNA yield is more than $80 \%$, with an uncertainty range of approximately $5 \%$. Under Arctic conditions, PFOA yield uncertainty ranges between 18 and $22 \%$, and PFNA shows a distribution ranging from 17 to $20 \%$. For both species, and especially PFNA, the range of yields due to differing photochemical conditions is much larger than the range of yields due to uncertainty under any given conditions. The greater impact of variability compared to uncertainty means that it is quantitatively viable to model the transport and chemical fate of emissions despite a relatively uncertain set of chemical reactions.

\subsection{Rate coefficient contributions to yield uncertainty}

Fractional contributions of individual reactions' rate coefficient uncertainties to the resulting yield uncertainty for PFOA and PFNA formation are summarized in Table 2. Most reactions in the mechanism contribute to uncertainty similarly for PFOA yield under urban conditions, with Reaction (16) having the largest contribution. The rate of this reaction between poly-fluorinated peroxy radicals and $\mathrm{RO}_{2}$ radicals to form a poly-fluorinated alcohol is one of the main factors determining whether the yielded product is PFNA or a shorter-chain PFCA (including PFOA), which makes it important for the uncertainties in yields for both of those end products. For ocean conditions, reaction rate constants (15), (16), (36), and (37) dominate the contributions to PFOA yield uncertainty. Arctic conditions show Reaction (37)'s rate constant uncertainty also playing a large role, but Reaction (34) also makes a substantial contribution. Reactions (15) and (16) represent a branching in the degradation chemistry where fluorinated peroxy radicals can either branch toward PFNA formation or PFOA and shorterchain PFCAs. Likewise, Reactions (34), (36), and (37) are 
Table 2. Fractional yield uncertainty contributions of rate constants (\%).

\begin{tabular}{|c|c|c|c|c|c|c|c|}
\hline $\begin{array}{l}\text { Rxn } \\
\#\end{array}$ & $\begin{array}{c}\text { PFOA } \\
\text { urban }\end{array}$ & $\begin{array}{l}\text { PFOA } \\
\text { ocean }\end{array}$ & $\begin{array}{l}\text { PFOA } \\
\text { Arctic }\end{array}$ & $\begin{array}{l}\text { PFNA } \\
\text { urban }\end{array}$ & $\begin{array}{l}\text { PFNA } \\
\text { ocean }\end{array}$ & $\begin{array}{l}\text { PNFA } \\
\text { Arctic }\end{array}$ & Reaction \\
\hline 1 & $<1$ & $<1$ & $<1$ & $<1$ & 2 & $<1$ & $\mathrm{C}_{8} \mathrm{~F}_{17} \mathrm{CH}_{2} \mathrm{C}(\mathrm{O}) \mathrm{H}+h v \rightarrow \mathrm{C}_{8} \mathrm{~F}_{17} \mathrm{CH}_{2} \mathrm{OO}$ \\
\hline 2 & $<1$ & $<1$ & $<1$ & 2 & 10 & $<1$ & $\mathrm{C}_{8} \mathrm{~F}_{17} \mathrm{CH}_{2} \mathrm{C}(\mathrm{O}) \mathrm{H}+\mathrm{OH} \rightarrow \mathrm{C}_{8} \mathrm{~F}_{17} \mathrm{CH}_{2} \mathrm{C}(\mathrm{O}) \mathrm{OO}$ \\
\hline 6 & $<1$ & $<1$ & $<1$ & 1 & 2 & $<1$ & $\mathrm{C}_{8} \mathrm{~F}_{17} \mathrm{CH}_{2} \mathrm{C}(\mathrm{O}) \mathrm{OO}+\mathrm{NO} \rightarrow \mathrm{C}_{8} \mathrm{~F}_{17} \mathrm{CH}_{2} \mathrm{OO}$ \\
\hline 7 & $<1$ & $<1$ & $<1$ & 1 & 2 & $<1$ & $\mathrm{C}_{8} \mathrm{~F}_{17} \mathrm{CH}_{2} \mathrm{C}(\mathrm{O}) \mathrm{OO}+\mathrm{HO}_{2} \rightarrow \mathrm{C}_{8} \mathrm{~F}_{17} \mathrm{CH}_{2} \mathrm{OO}$ \\
\hline 8 & 7 & $<1$ & $<1$ & $<1$ & 2 & $<1$ & $\mathrm{C}_{8} \mathrm{~F}_{17} \mathrm{CH}_{2} \mathrm{C}(\mathrm{O}) \mathrm{OO}+\mathrm{HO}_{2} \rightarrow \mathrm{C}_{8} \mathrm{~F}_{17} \mathrm{CH}_{2} \mathrm{C}(\mathrm{O}) \mathrm{OH}$ \\
\hline 10 & 5 & $<1$ & $<1$ & 8 & 2 & 4 & $\mathrm{C}_{8} \mathrm{~F}_{17} \mathrm{CH}_{2} \mathrm{C}(\mathrm{O}) \mathrm{OO}+\mathrm{RO}_{2} \rightarrow \mathrm{C}_{8} \mathrm{~F}_{17} \mathrm{CH}_{2} \mathrm{C}(\mathrm{O}) \mathrm{OH}$ \\
\hline 11 & $<1$ & $<1$ & $<1$ & 2 & 2 & 5 & $\mathrm{C}_{8} \mathrm{~F}_{17} \mathrm{CH}_{2} \mathrm{C}(\mathrm{O}) \mathrm{OH}+\mathrm{OH} \rightarrow \mathrm{C}_{8} \mathrm{~F}_{17} \mathrm{CH}_{2} \mathrm{OO}$ \\
\hline 12 & $<1$ & $<1$ & $<1$ & 2 & 2 & 4 & $\mathrm{C}_{8} \mathrm{~F}_{17} \mathrm{CH}_{2} \mathrm{C}(\mathrm{O}) \mathrm{OH}+\mathrm{OH} \rightarrow \mathrm{C}_{8} \mathrm{~F}_{17} \mathrm{C}(\mathrm{O}) \mathrm{H}$ \\
\hline 14 & $<1$ & 7 & $<1$ & $<1$ & 1 & 27 & $\mathrm{C}_{8} \mathrm{~F}_{17} \mathrm{CH}_{2} \mathrm{OO}+\mathrm{NO} \rightarrow \mathrm{C}_{8} \mathrm{~F}_{17} \mathrm{CH}_{2} \mathrm{O}$ \\
\hline 15 & $<1$ & 10 & $<1$ & $<1$ & 3 & $<1$ & $\mathrm{C}_{8} \mathrm{~F}_{17} \mathrm{CH}_{2} \mathrm{OO}+\mathrm{RO}_{2} \rightarrow \mathrm{C}_{8} \mathrm{~F}_{17} \mathrm{CH}_{2} \mathrm{O}$ \\
\hline 16 & 23 & 48 & $<1$ & 15 & 3 & 57 & $\mathrm{C}_{8} \mathrm{~F}_{17} \mathrm{CH}_{2} \mathrm{OO}+\mathrm{RO}_{2} \rightarrow \mathrm{C}_{8} \mathrm{~F}_{17} \mathrm{CH}_{2} \mathrm{OH}$ \\
\hline 29 & 6 & $<1$ & $<1$ & 9 & 3 & $<1$ & $\mathrm{C}_{8} \mathrm{~F}_{17} \mathrm{C}(\mathrm{O}) \mathrm{OO}+\mathrm{NO} \rightarrow \mathrm{C}_{8} \mathrm{~F}_{17} \mathrm{OO}$ \\
\hline 30 & $<1$ & $<1$ & $<1$ & 1 & 1 & $<1$ & $\mathrm{C}_{8} \mathrm{~F}_{17} \mathrm{C}(\mathrm{O}) \mathrm{OO}+\mathrm{HO}_{2} \rightarrow \mathrm{C}_{8} \mathrm{~F}_{17} \mathrm{C}(\mathrm{O}) \mathrm{OH}$ \\
\hline 34 & 5 & $<1$ & 35 & 1 & 3 & $<1$ & $\mathrm{C}_{8} \mathrm{~F}_{17} \mathrm{OO}+\mathrm{NO} \rightarrow \mathrm{C}_{8} \mathrm{~F}_{17} \mathrm{O}$ \\
\hline 35 & 3 & 2 & $<1$ & 3 & 3 & $<1$ & $\mathrm{C}_{8} \mathrm{~F}_{17} \mathrm{OO}+\mathrm{HO}_{2} \rightarrow \mathrm{C}_{8} \mathrm{~F}_{17} \mathrm{O}$ \\
\hline 36 & $<1$ & 13 & $<1$ & 2 & 3 & $<1$ & $\mathrm{C}_{8} \mathrm{~F}_{17} \mathrm{OO}+\mathrm{RO}_{2} \rightarrow \mathrm{C}_{8} \mathrm{~F}_{17} \mathrm{O}$ \\
\hline 37 & 8 & 18 & 63 & 2 & 1 & $<1$ & $\mathrm{C}_{8} \mathrm{~F}_{17} \mathrm{OO}+\mathrm{RO}_{2} \rightarrow \mathrm{C}_{8} \mathrm{~F}_{17} \mathrm{OH}$ \\
\hline
\end{tabular}

at a branching point where shorter peroxy radicals can either react to form PFOA or even shorter-chain PFCAs.

PFNA yield uncertainties are dominated by a different subset of the reaction mechanism for the Arctic environment, and see a contribution from a large number of reaction rates for the urban and ocean cases, led by Reactions (16) and (2) (reaction of $\mathrm{OH}$ with the initial precursor), respectively. In the Arctic, reaction rate constant (16) uncertainty dominates, with Reaction (14) (another peroxy radical reaction) also contributing significantly. In summary, we determine for the first time the dominant sources of uncertainties in theoretical maximum yields of PFOA and PFNA, finding that rate constants of reactions of $\mathrm{NO}$ and $\mathrm{RO}_{2}$ with poly- and per-fluorinated peroxy radicals are the leading sources in the degradation chemistry.

\subsection{Regime behavior in PFNA yields and formation times}

Figure 4 shows calculated PFNA yield for each GEOS-Chem grid box and associated time of formation for summer conditions, with DBSCAN algorithm clusters in the $\mathrm{OH}-\mathrm{HO}_{2}-\mathrm{NO}$ space of the sample of summer atmospheric photochemical conditions. Two distinct regimes appear in the plotted space, one in which yield is low across formation times, and one in which longer formation times are associated with higher yields. As Fig. 4 shows, the clusters in $\mathrm{OH}-\mathrm{HO}_{2}-\mathrm{NO}$ space correspond to regimes of formation for PFNA, and to spatial regions of the atmosphere. Each of the two clusters respectively compose the majority of each of the two regimes in PFNA yield - time of formation space. Figure $4 \mathrm{~b}$ shows that the same clusters also correspond to Arctic and lowerlatitude environments, respectively, indicating a distinct pho-

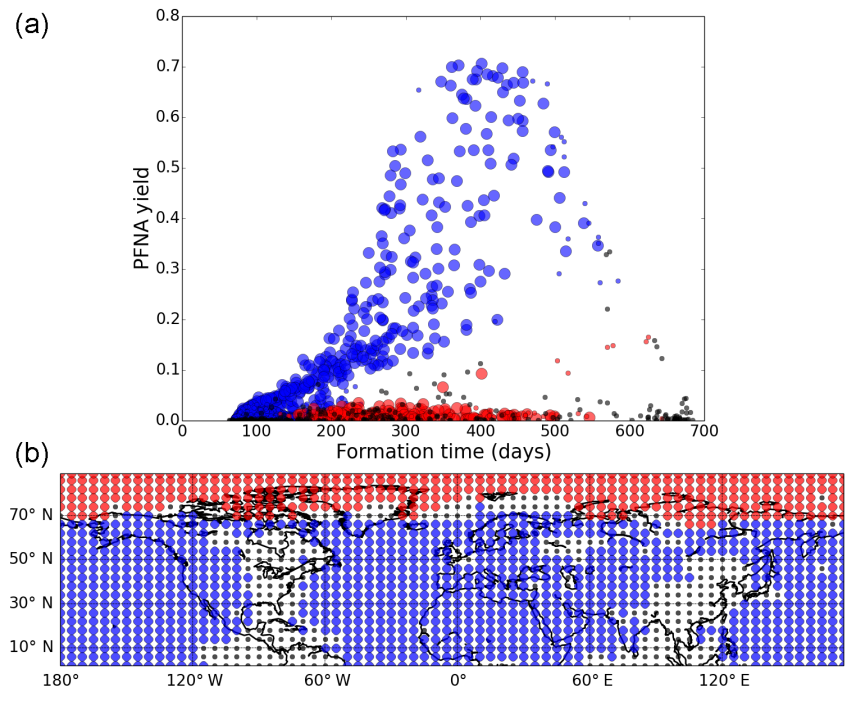

Figure 4. (a) Each photochemical environment plotted in yieldformation time space. Color indicates membership of a cluster in $\mathrm{OH}-\mathrm{HO}_{2}-\mathrm{NO}$ space. Black circles indicate unclustered points. (b) Geographic location of clusters. Colors correspond to the same clusters in both figures.

tochemical environment for PFCA formation in the Arctic atmosphere that to our knowledge has not been discussed in previous studies. Within the lower-latitude mode, PFNA yield increases with decreasing NO concentrations, with the lowest yields occurring over land in more polluted areas and the highest yields occurring over the oceans far from $\mathrm{NO}_{x}$ sources. 

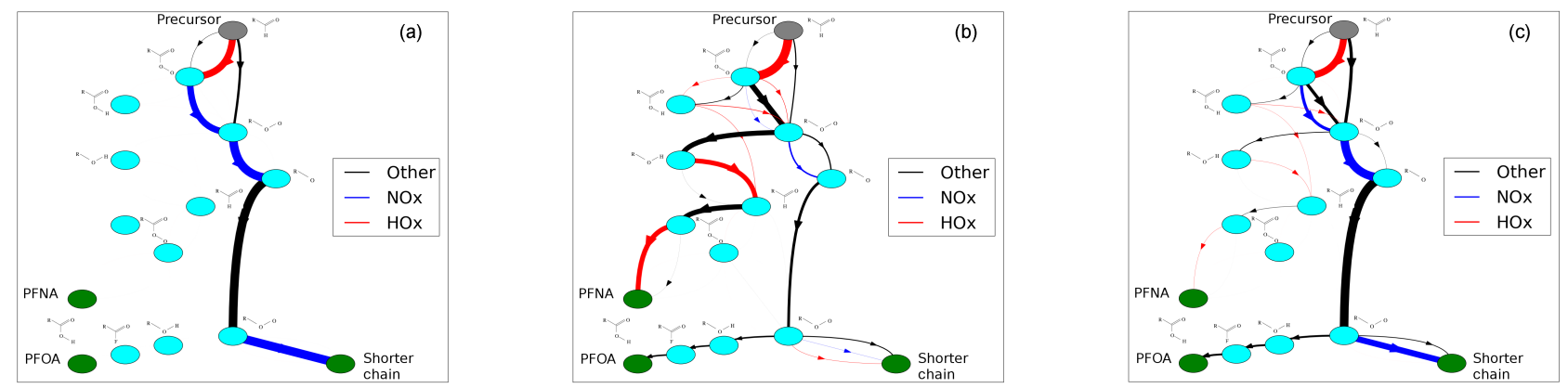

Figure 5. Total flux through each reaction for the degradation mechanism for urban (a), ocean (b), and Arctic (c) conditions. Each line represents a reaction, with the color of the line indicating the photochemical family of the non-fluorinated reactant, and the thickness of the line is proportional to the total flux through the reaction over the course of a simulation.

\section{Discussion}

We find a wide variety of theoretical maximum yields for both PFOA and PFNA across the Northern Hemisphere's photochemical environments. With many regions yielding less than $1 \%$ of each due to the presence of large enough quantities of $\mathrm{NO}_{x}$, but PFOA yields of up to $40 \%$ and PFNA yields of up to $80 \%$ in some areas, the specific photochemical environment has a strong effect on the capacity of the atmosphere to yield lcPFCAs from the degradation of emitted precursors. We find that the parametric uncertainty in these theoretical maximum yields depends on the environment as well, but is at most on the order of a few percent, much smaller than the variability caused by the diversity in photochemical environments.

We find two distinct regimes of PFNA formation capacity in the atmospheric environment, which correspond to photochemical environments found in the Arctic and at lower latitudes, respectively. The former shows relatively constant theoretical maximum yields across all of the conditions within the Arctic, with a large range of formation times that are independent of the yields. The second regime, on the other hand, shows that at lower latitudes there is a large range of both yields and formation times, and that longer formation times are associated with higher theoretical maximum yields. Within this regime, the higher the concentration of $\mathrm{NO}$, the shorter the formation time and the lower the yield capacity. Figure 5 illustrates this behavior, showing the flux through different reactions in the chemical mechanism over the course of a box model run at the conditions of the three representative environments introduced in Sect. 2.3. The nodes in the diagram represent intermediate or endproduct species in fluorotelomer degradation, while the lines represent the reaction fluxes, with the thickness of the lines proportional to the flux. Figure $5 \mathrm{a}$ and $\mathrm{b}$ show that at lower latitudes the amount of NO present strongly drives fluxes towards either short-chain PFCAs (urban, high-NO conditions) or long-chain PFCAs (ocean, low-NO conditions). The reactions of peroxy radicals with $\mathrm{NO}$ are too fast in the pres- ence of substantial $\mathrm{NO}_{x}$ to allow branching toward PFNA or PFOA formation.

The highest theoretical maximum yields and longest formation times are associated with conditions over the oceans far from sources and far from common photochemical pollution sources. Emissions of lcPFCA precursors into polluted air masses reduces the potential for those precursors to form lcPFCAs. Put another way, emissions of precursors in otherwise less-polluted regions are conducive to more lcPFCA formation per precursor emitted.

The calculations that we present are of lcPFCA theoretical maximum yields, and are the upper limits of PFOA and PFNA formation for given atmospheric conditions. In the atmosphere, non-chemical loss processes that we neglect in our model limit actual lcPFCA yields compared to their theoretical maxima. In the case of PFNA, as the areas with highest theoretical maximum yields are associated with the longest formation times, they will see larger discrepancies between theoretical and actual yields than areas with lower theoretical maximum yields. Although regions far from $\mathrm{NO}_{x}$ sources have the greatest capacity for PFNA formation, they also are most vulnerable to having concentrations of degradation intermediates reduced by wet deposition and scavenging before the degradation has reached an end product (e.g. over the equatorial oceans).

We calculate the theoretical maximum yields of lcPFCAs from precursor degradation under many atmospheric conditions, but the degradation mechanism is indicative of daytime chemistry. In the Arctic during the summer this is not problematic, but in the winter it neglects the possibility of significant nighttime chemistry involving species such as $\mathrm{N}_{2} \mathrm{O}_{5}$ and $\mathrm{H}_{2} \mathrm{O}_{2}$ that to our knowledge has not been studied. Future research could put theoretical or experimental constraints on the possible importance of these reactions.

With respect to theoretical maximum yields in different seasons, winter conditions lead to lower yields of both PFNA and PFOA, sometimes by orders of magnitude. Young et al. (2007) report a similar seasonal dependence from the Devon Ice Cap, with summer concentrations of PFOA and PFNA 
being an order of magnitude higher than winter concentrations in the accumulated snow profiles. For the years 2004 and 2005, the average winter PFNA concentration in those snow measurements is 18 times smaller than the average summer concentration, and for PFOA the winter average is 7 times smaller. In our calculations, those same ratios over the Canadian Arctic are 18 and 10, respectively. As the longchain PFCA deposited on the Devon Ice Cap is most likely atmospherically generated (Young et al., 2007; Goss, 2008), this suggests consistency between our calculations of PFNA and PFOA theoretical yields and observational evidence of lcPFCA yielded through formation in the atmosphere.

The importance of the photochemical environment to lcPFCA formation, particularly the importance of the presence of $\mathrm{NO}_{x}$, means that future air pollution reductions or increases could impact atmospheric lcPFCA yields. For instance, large reductions in $\mathrm{NO}_{x}$ emissions would lead to more lcPFCA products. However, given our results, we find that $\mathrm{NO}_{x}$ concentration reductions would have to be on the order-of-magnitude scale to affect theoretical maximum yields significantly.

We estimate uncertainty ranges in theoretical maximum yields for PFOA and PFNA under the ocean case conditions to be $17-22$ and $78-85 \%$, respectively, with most of the uncertainty for PFOA stemming from uncertainty in rate constants at a branching point in the degradation mechanism. In the Arctic case conditions, PFOA maximum yield has a similar value and level of uncertainty as for ocean conditions, while PFNA yields have a much lower value and slightly lower level of uncertainty. Again, under these conditions, the majority of the uncertainty is due to uncertainty in two peroxy radical reaction rate constants at branching points in the mechanism. Better understanding the quantitative relationship between rate constants at these branching points will have the greatest effect on reducing the parametric uncertainty in theoretical maximum yields.

We quantify the parametric uncertainty in theoretical maximum yields, which depend exclusively on the rate constants. In the atmosphere, where deposition can play an important role in lcPFCA formation, many other sources of uncertainty for yields will arise, such as rates of deposition, frequency of rainout and washout events, and solubility and aqueous chemistry of intermediate species, among others. While the uncertainty due to rate constants is quantifiable based on the chemistry used in our calculations, any missing reactions in the degradation chemistry will be unquantifiable. If our mechanism is incomplete due to currently unidentified reactions, our estimates of uncertainty would underestimate the full uncertainty of the chemistry. Our estimates of the variability of lcPFCA theoretical maximum yields in the atmosphere are also uncertain due to uncertainty in the photochemical conditions used, which are output from the GEOS-Chem model. The uncertainty in GEOS-Chem calculations of photochemical environment is not quantified here, nor is the uncertainty due the model grid box size's inherent smoothing of photochemical extremes.

The maximum yields calculated above allow us to estimate potential upper limits on the amount of atmospherically produced long-chain PFCAs given the emitted precursor quantities. The current estimate (Wang et al., 2014a) of volatile $8: 2$ fluorotelomer compound global releases has an upper bound of 500 tyear $^{-1}$ for the year 2010, the only year for which such a detailed estimate is available. Given the theoretical maximum yields we have calculated, this translates to $50 \mathrm{t} \mathrm{year}^{-1}$ of lcPFCA produced atmospherically based on median yield values from our calculations. This may be an overestimate, however, considering the spatial distribution of theoretical maximum yields. In regions where precursors are emitted (over continental North America, Europe, and Asia), theoretical maximum yields are less than $1 \%$. If the precursors and intermediates reside in this type of environment for extended periods of time, the upper limit of atmospheric lcPFCA production could be $5 \mathrm{tyear}^{-1}$ or lower. However, larger yields can result when precursors are transported to higher-yield environments. These estimates of upper limit atmospheric production scale linearly with emissions, so emissions rates lower than the upper bound estimates would lead to correspondingly lower atmospheric production maxima. Depending on how long precursor and intermediate species reside in the different atmospheric regions and the distribution of emissions, yields of lcPFCAs can vary greatly. To illustrate this point, Fig. 6 shows the time series of the fate of a unit of fluorotelomer precursor released from the eastern US and following a trajectory calculated by the HYSPLIT dispersion model, through our photochemical environments. Starting in a relatively high- $\mathrm{NO}_{x}$ environment, the precursor is quickly reacted and short-chain compounds form quickly at the beginning. As the parcel of air is transported over the Atlantic Ocean and poleward, long-chain PFCAs begin to form more quickly. The remaining intermediates at the end of this period have the potential to form much more PFOA and PFNA depending on the future fate of the air parcel. Despite emission into a very low-maximum yield environment, the transport is sufficiently fast to allow long-chain PFCA formation.

We quantify the theoretical maximum yields of formation of lcPFCAs from fluorotelomer precursor, but there are other precursors that follow different degradation schemes and would therefore yield PFCAs in different quantities for the same environment. Precursors such as FOSAs and FOSEs are found along with FTOHs in the remote atmosphere (Shoeib et al., 2006) and are also precursors to perfluorooctanesulfonic acid (PFOS). Some fluorotelomer precursors such as fluorotelomer olefins follow only a subsection of our reaction mechanism because of their structure, and would have higher theoretical maximum yields.

The uncertainty and variability estimates that we present indicate quantitatively that the most important piece of information for calculating atmospherically formed PFCAs 
Table 3. Theoretical maximum yield calculations extended to other precursor lengths and product lengths for an environment with PFNA yield of 18 and PFOA yield of $20 \%$.

\begin{tabular}{lrrrr}
\hline Product & $12: 2$ Precursor & $10: 2$ Precursor & $8: 2$ Precursor & $6: 2$ Precursor \\
\hline PFTrDA & 0.18 & 0.00 & 0.00 & 0.00 \\
PFDoDA & 0.20 & 0.00 & 0.00 & 0.00 \\
PFUnDA & 0.15 & 0.18 & 0.00 & 0.00 \\
PFDA & 0.11 & 0.20 & 0.00 & 0.00 \\
PFNA & 0.09 & 0.15 & 0.18 & 0.00 \\
PFOA & 0.07 & 0.11 & 0.20 & 0.00 \\
PFHeA & 0.05 & 0.09 & 0.15 & 0.18 \\
PFHxA & 0.04 & 0.07 & 0.11 & 0.20 \\
PFPeA & 0.03 & 0.05 & 0.09 & 0.15 \\
PFDA & 0.02 & 0.04 & 0.07 & 0.11 \\
PFPrA & 0.02 & 0.03 & 0.05 & 0.09 \\
TFA & 0.01 & 0.02 & 0.04 & 0.07 \\
Remainder & 0.04 & 0.07 & 0.12 & 0.20 \\
\hline
\end{tabular}
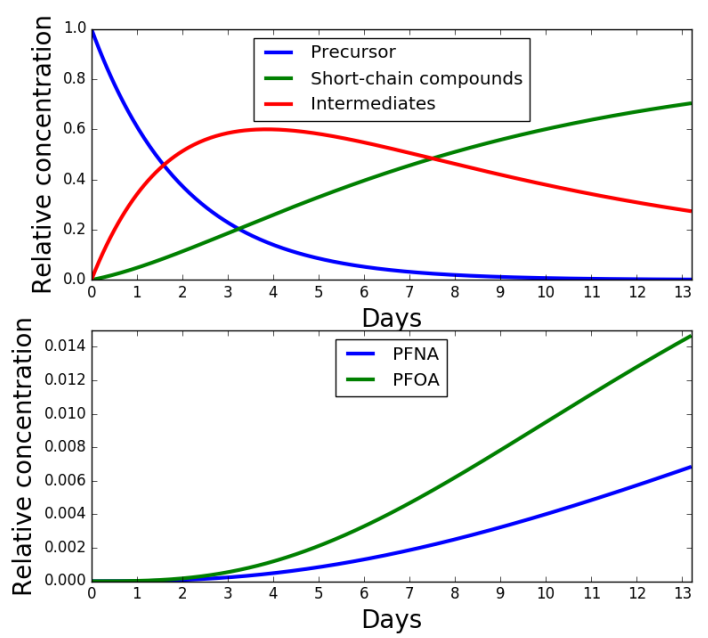

Figure 6. Fluorotelomer precursor chemical fate along HYSPLIT trajectory through summertime photochemical environments. After two weeks, yields of PFOA and PFNA are approximately 1.5 and $0.7 \%$, respectively, with more than $20 \%$ of the initial precursor still in an intermediate form which will undergo further reactions.

is their photochemical environment, and that explicitly accounting for transport in the atmosphere on top of chemistry would give accurate estimates of yielded PFCAs despite uncertainty in the rates of the chemistry involved. This means that the approach of previous studies that use spatially resolved models (Wallington et al., 2006; Yarwood et al., 2007) is one the most important to our understanding of atmospherically generated PFCAs and should be continued in the future. Our results also show, however, that accounting only for regional-scale transport, as in Yarwood et al. (2007), could miss an important fraction of the atmospherically formed long-chain PFCAs, since the capacity for remote atmospheric conditions to form them is so high. Continued quantitative study of the chemistry of atmospheric PFCA formation has further value over the previous work. Of particular value would be updating the chemical mechanism, accounting for the changes in the photochemical environment brought on by synoptic variability, and accounting for anthropogenic emissions changes relevant to both $\mathrm{HO}_{x}-\mathrm{NO}_{x}$ photochemistry and PFCAs themselves.

Future calculations with a detailed chemical transport model, that also accounts for both deposition processes and transport in the atmosphere, would allow for a best estimate of total lcPFCA production in the atmosphere over time. While the US EPA Stewardship Program strives to greatly reduce lcPFCA precursors emitted due to American manufacturers, there remains the possibility of growth of precursor production in Asia in the future, meaning that atmospheric lcPFCA formation could become increasingly important as a source globally and for the Arctic. In the future, if production does shift to shorter-chain fluorotelomer products, our findings will apply to correspondingly shorter-chain PFCAs formed in the atmosphere, as the chemistry studied is analogous across the homologue series. With the assumption that relative rates at the branching points do not depend on chain length, our calculations can be extended to longer and shorter precursor homologues and correspondingly longer and shorter product homologues. If $Y(9)$ and $Y(8)$ are our calculated maximum yields for PFNA and PFOA, respectively, then the fraction $f_{\mathrm{PFCA}}$ of PFCA formation from the "unzipping" step of the mechanism is

$f_{\mathrm{PFCA}}=\frac{Y(8)}{(1-Y(9))}$.

Knowing this fraction, yield calculations can be extended to shorter and shorter chain PFCA products using the formula

$Y(X)=f_{\mathrm{PFCA}}\left(1-\sum_{i=x+1}^{\text {longer }} Y(i)\right)$, 
where the theoretical maximum yield at a given product chain length can be calculated based on the yields of the longer-chain products in a given environment.

As an example, Table 3 shows the extension of the Arctic case where the theoretical maximum yields of PFNA and PFOA are 18 and $20 \%$, respectively.

Wallington et al. (2006) estimated $0.4 \mathrm{tyear}^{-1}$ of PFOA entering the Arctic due to atmospheric production via $8: 2$ FTOH degradation; the amount entering the Arctic is less than half of global atmospheric PFOA production. This was calculated assuming $1000 \mathrm{tyear}^{-1}$ of FTOH emitted to the atmosphere, which is twice the current upper bound of total fluorotelomer emissions to air. Wania (2007) estimated that the amount of atmospherically generated PFCAs deposited in the Arctic peaked in 2005 at 0.154 tyear $^{-1}$, and that $11-$ 21 tyear $^{-1}$ is transported to the Arctic via the ocean. Both of these studies estimate atmospherically generated quantities of lcPFCAs which fall reasonably beneath our calculated theoretical maxima. Our results indicate, however, that the region over the oceans is the leading atmospheric environment for lcPFCA formation, meaning that transport to the Arctic via the ocean can be importantly affected by lcPFCAs formed atmospherically at lower latitudes. A detailed coupled atmosphere-ocean model could give important insights to future studies. We quantify variability in atmospherically formed PFCAs but direct emissions and transport of PFOA and its salts are also environmentally relevant, as transport to remote regions through the ocean has historically likely been dominated by these direct emissions (Wania, 2007).

\section{Conclusions}

We calculate PFOA and PFNA formation theoretical maximum yields for the degradation of precursor species at a representative sample of atmospheric conditions, and estimate uncertainties in such calculations for urban, ocean, and Arctic conditions. We find that atmospheric conditions farther from pollution sources have both higher capacities to form long-chain PFCAs and higher uncertainties in those capacities. The greatest uncertainty reductions through reaction rate determinations can be achieved by better quantifying rate constants at the branching points of the degradation chemistry. We find that there are distinct regimes of PFNA formation behavior in different photochemical environments, dictated by the quantities of $\mathrm{HO}_{x}$ and $\mathrm{NO}_{x}$ species, but less variability in the formation of PFOA.
While we study the daytime chemistry in detail, future studies should investigate the role of nighttime chemistry in lcPFCA formation. The role of non-chemical removal processes from the atmosphere is also an important part of atmospheric lcPFCA formation, and its environmental connection to yields of formation should be investigated.

Our calculations of theoretical maximum yields indicate that most likely less than $10 \%$ of emitted precursor can reach lcPFCA end products in the Northern Hemisphere, even ignoring non-chemical losses. This results in an upper bound of 2-50 tyear $^{-1}$ of lcPFCA (depending on quantity of emitted precursor) produced in the atmosphere via degradation of fluorotelomer products. Only a fraction of that is destined to directly deposit in the Arctic. While the atmosphere is a potentially growing source of 1cPFCA in the Arctic, oceanic transport of directly emitted, and to a lesser extent low-latitude atmospherically generated, PFCAs are likely more important pathways to the Arctic for IcPFCA.

Data availability. Data and code from this publication are publicly available at https://github.com/thackray/pfca_precursors_data_acp (Thackray, 2017). 


\section{Appendix A}

Table A1. List of reactions.

\begin{tabular}{|c|c|c|c|}
\hline Reaction & Rate constant expression & Uncertainty & Source \\
\hline (1) $\mathrm{C}_{8} \mathrm{~F}_{17} \mathrm{CH}_{2} \mathrm{C}(\mathrm{O}) \mathrm{H}+h v 350 \rightarrow \mathrm{C}_{8} \mathrm{~F}_{17} \mathrm{CH}_{2} \mathrm{OO}$ & $1.5 \times 10^{-21}\left(\mathrm{~cm}^{2}\right.$ photon $\left.^{-1} \mathrm{~s}^{-1}\right)$ & $7.5 \times 10^{-22}$ & a \\
\hline (2) $\mathrm{C}_{8} \mathrm{~F}_{17} \mathrm{CH}_{2} \mathrm{C}(\mathrm{O}) \mathrm{H}+\mathrm{OH} \rightarrow \mathrm{C}_{8} \mathrm{~F}_{17} \mathrm{CH}_{2} \mathrm{C}(\mathrm{O}) \mathrm{OO}$ & $2.0 \times 10^{-12}\left(\mathrm{~cm}^{3} \mathrm{~s}^{-1}\right)$ & $0.4 \times 10^{-12}$ & a \\
\hline (3) $\mathrm{C}_{8} \mathrm{~F}_{17} \mathrm{CH}_{2} \mathrm{C}(\mathrm{O}) \mathrm{H}+\mathrm{Cl} \rightarrow \mathrm{C}_{8} \mathrm{~F}_{17} \mathrm{CH}_{2} \mathrm{C}(\mathrm{O}) \mathrm{OO}$ & $1.9 \times 10^{-11}\left(\mathrm{~cm}^{3} \mathrm{~s}^{-1}\right)$ & $0.2 \times 10^{-11}$ & a \\
\hline (4) $\mathrm{C}_{8} \mathrm{~F}_{17} \mathrm{CH}_{2} \mathrm{C}(\mathrm{O}) \mathrm{OO}+\mathrm{NO}_{2} \rightarrow \mathrm{C}_{8} \mathrm{~F}_{17} \mathrm{CH}_{2} \mathrm{C}(\mathrm{O}) \mathrm{OONO}_{2}$ & $1.1 \times 10^{-11}(298 . / T)\left(\mathrm{cm}^{3} \mathrm{~s}^{-1}\right)$ & $0.1 \times 10^{-11}$ & $\mathrm{c}$ \\
\hline (5) $\mathrm{C}_{8} \mathrm{~F}_{17} \mathrm{CH}_{2} \mathrm{C}(\mathrm{O}) \mathrm{OONO}_{2} \rightarrow \mathrm{C}_{8} \mathrm{~F}_{17} \mathrm{CH}_{2} \mathrm{C}(\mathrm{O}) \mathrm{OO}$ & $2.8 \times 10^{16} \exp (T /-13580)\left(\mathrm{s}^{-1}\right)$ & $0.2 \times 10^{16}$ & $\mathrm{c}$ \\
\hline (6) $\mathrm{C}_{8} \mathrm{~F}_{17} \mathrm{CH}_{2} \mathrm{C}(\mathrm{O}) \mathrm{OO}+\mathrm{NO} \rightarrow \mathrm{C}_{8} \mathrm{~F}_{17} \mathrm{CH}_{2} \mathrm{OO}$ & $7 \times 10^{-12} \exp (T / 340)\left(\mathrm{cm}^{3} \mathrm{~s}^{-1}\right)$ & $0.5 \times 10^{-12}$ & $\mathrm{c}$ \\
\hline (7) $\mathrm{C}_{8} \mathrm{~F}_{17} \mathrm{CH}_{2} \mathrm{C}(\mathrm{O}) \mathrm{OO}+\mathrm{HO}_{2} \rightarrow \mathrm{C}_{8} \mathrm{~F}_{17} \mathrm{CH}_{2} \mathrm{OO}$ & $3.1 \times 10^{-13} \exp (T / 1040)\left(\mathrm{cm}^{3} \mathrm{~s}^{-1}\right)$ & $0.3 \times 10^{-13}$ & $\mathrm{c}, \mathrm{a}$ \\
\hline (8) $\mathrm{C}_{8} \mathrm{~F}_{17} \mathrm{CH}_{2} \mathrm{C}(\mathrm{O}) \mathrm{OO}+\mathrm{HO}_{2} \rightarrow \mathrm{C}_{8} \mathrm{~F}_{17} \mathrm{CH}_{2} \mathrm{C}(\mathrm{O}) \mathrm{OH}$ & $1.2 \times 10^{-13} \exp (T / 1040)\left(\mathrm{cm}^{3} \mathrm{~s}^{-1}\right)$ & $0.1 \times 10^{-13}$ & $\mathrm{c}, \mathrm{a}$ \\
\hline (9) $\mathrm{C}_{8} \mathrm{~F}_{17} \mathrm{CH}_{2} \mathrm{C}(\mathrm{O}) \mathrm{OO}+\mathrm{CH}_{3} \mathrm{O}_{2} \rightarrow \mathrm{C}_{8} \mathrm{~F}_{17} \mathrm{CH}_{2} \mathrm{OO}$ & $1.8 \times 10^{-12} \exp (T / 500)\left(\mathrm{cm}^{3} \mathrm{~s}^{-1}\right)$ & $3.6 \times 10^{-13}$ & $\mathrm{~b}$ \\
\hline (10) $\mathrm{C}_{8} \mathrm{~F}_{17} \mathrm{CH}_{2} \mathrm{C}(\mathrm{O}) \mathrm{OO}+\mathrm{CH}_{3} \mathrm{O}_{2} \rightarrow \mathrm{C}_{8} \mathrm{~F}_{17} \mathrm{CH}_{2} \mathrm{C}(\mathrm{O}) \mathrm{OH}$ & $2.0 \times 10^{-13} \exp (T / 500)\left(\mathrm{cm}^{3} \mathrm{~s}^{-1}\right)$ & $4.0 \times 10^{-14}$ & $\mathrm{~b}$ \\
\hline (11) $\mathrm{C}_{8} \mathrm{~F}_{17} \mathrm{CH}_{2} \mathrm{C}(\mathrm{O}) \mathrm{OH}+\mathrm{OH} \rightarrow \mathrm{C}_{8} \mathrm{~F}_{17} \mathrm{CH}_{2} \mathrm{OO}$ & $2.02 \times 10^{-14} \exp (T / 920)\left(\mathrm{cm}^{3} \mathrm{~s}^{-1}\right)$ & $0.6 \times 10^{-14}$ & $\mathrm{~b}$ \\
\hline (12) $\mathrm{C}_{8} \mathrm{~F}_{17} \mathrm{CH}_{2} \mathrm{C}(\mathrm{O}) \mathrm{OH}+\mathrm{OH} \rightarrow \mathrm{C}_{8} \mathrm{~F}_{17} \mathrm{C}(\mathrm{O}) \mathrm{H}$ & $1.13 \times 10^{-14} \exp (T / 920)\left(\mathrm{cm}^{3} \mathrm{~s}^{-1}\right)$ & $0.32 \times 10^{-14}$ & $\mathrm{~b}$ \\
\hline (13) $\mathrm{C}_{8} \mathrm{~F}_{17} \mathrm{CH}_{2} \mathrm{OO}+\mathrm{HO}_{2} \rightarrow \mathrm{C}_{8} \mathrm{~F}_{17} \mathrm{CH}_{2} \mathrm{OOH}$ & $4.1 \times 10^{-13} \exp (T / 750)\left(\mathrm{cm}^{3} \mathrm{~s}^{-1}\right)$ & $0.4 \times 10^{-13}$ & $\mathrm{c}$ \\
\hline (14) $\mathrm{C}_{8} \mathrm{~F}_{17} \mathrm{CH}_{2} \mathrm{OO}+\mathrm{NO} \rightarrow \mathrm{C}_{8} \mathrm{~F}_{17} \mathrm{CH}_{2} \mathrm{O}$ & $2.8 \times 10^{-12} \exp (T / 300)\left(\mathrm{cm}^{3} \mathrm{~s}^{-1}\right)$ & $0.14 \times 10^{-12}$ & c \\
\hline (15) $\mathrm{C}_{8} \mathrm{~F}_{17} \mathrm{CH}_{2} \mathrm{OO}+\mathrm{CH}_{3} \mathrm{O}_{2} \rightarrow \mathrm{C}_{8} \mathrm{~F}_{17} \mathrm{CH}_{2} \mathrm{O}$ & $1.9 \times 10^{-14} \exp (T / 390)\left(\mathrm{cm}^{3} \mathrm{~s}^{-1}\right)$ & $0.26 \times 10^{-14}$ & $\mathrm{~b}$ \\
\hline (16) $\mathrm{C}_{8} \mathrm{~F}_{17} \mathrm{CH}_{2} \mathrm{OO}+\mathrm{CH}_{3} \mathrm{O}_{2} \rightarrow \mathrm{C}_{8} \mathrm{~F}_{17} \mathrm{CH}_{2} \mathrm{OH}$ & $7.6 \times 10^{-14} \exp (T / 390)\left(\mathrm{cm}^{3} \mathrm{~s}^{-1}\right)$ & $1.06 \times 10^{-14}$ & $\mathrm{~b}$ \\
\hline (17) $\mathrm{C}_{8} \mathrm{~F}_{17} \mathrm{CH}_{2} \mathrm{OH}+\mathrm{OH} \rightarrow \mathrm{C}_{8} \mathrm{~F}_{17} \mathrm{C}(\mathrm{O}) \mathrm{H}$ & $1.02 \times 10^{-13} \exp (T /-350)\left(\mathrm{cm}^{3} \mathrm{~s}^{-1}\right)$ & $0.1 \times 10^{-13}$ & $\mathrm{~d}$ \\
\hline (18) $\mathrm{C}_{8} \mathrm{~F}_{17} \mathrm{CH}_{2} \mathrm{OH}+\mathrm{Cl} \rightarrow \mathrm{C}_{8} \mathrm{~F}_{17} \mathrm{C}(\mathrm{O}) \mathrm{H}$ & $6.5 \times 10^{-13} \exp (T /-350)\left(\mathrm{cm}^{3} \mathrm{~s}^{-1}\right)$ & $1.0 \times 10^{-13}$ & $\mathrm{~b}$ \\
\hline (19) $\mathrm{C}_{8} \mathrm{~F}_{17} \mathrm{CH}_{2} \mathrm{OOH}+\mathrm{OH} \rightarrow \mathrm{C}_{8} \mathrm{~F}_{17} \mathrm{CH}_{2} \mathrm{OO}$ & $4.0 \times 10^{-12} \exp (T / 200)\left(\mathrm{cm}^{3} \mathrm{~s}^{-1}\right)$ & $1.0 \times 10^{-12}$ & $\mathrm{~b}$ \\
\hline (20) $\mathrm{C}_{8} \mathrm{~F}_{17} \mathrm{CH}_{2} \mathrm{O} \rightarrow \mathrm{C}_{8} \mathrm{~F}_{17} \mathrm{OO}$ & $2.5 \times 10^{1}\left(\mathrm{~s}^{-1}\right)$ & $0.1 \times 10^{1}$ & $\mathrm{~d}$ \\
\hline (21) $\mathrm{C}_{8} \mathrm{~F}_{17} \mathrm{C}(\mathrm{O}) \mathrm{H}+h \nu 350 \rightarrow \mathrm{C}_{8} \mathrm{~F}_{17} \mathrm{OO}$ & $1.6 \times 10^{-21}\left(\mathrm{~cm}^{2}\right.$ photon $\left.^{-1} \mathrm{~s}^{-1}\right)$ & $0.12 \times 10^{-21}$ & $\mathrm{a}$ \\
\hline (22) $\mathrm{C}_{8} \mathrm{~F}_{17} \mathrm{C}(\mathrm{O}) \mathrm{H}+\mathrm{OH} \rightarrow \mathrm{C}_{8} \mathrm{~F}_{17} \mathrm{C}(\mathrm{O}) \mathrm{OO}$ & $6.1 \times 10^{-13}\left(\mathrm{~cm}^{3} \mathrm{~s}^{-1}\right)$ & $0.5 \times 10^{-13}$ & a \\
\hline (23) $\mathrm{C}_{8} \mathrm{~F}_{17} \mathrm{C}(\mathrm{O}) \mathrm{H}+\mathrm{Cl} \rightarrow \mathrm{C}_{8} \mathrm{~F}_{17} \mathrm{C}(\mathrm{O}) \mathrm{OO}$ & $2.8 \times 10^{-12}\left(\mathrm{~cm}^{3} \mathrm{~s}^{-1}\right)$ & $0.7 \times 10^{-12}$ & a \\
\hline (24) $\mathrm{C}_{8} \mathrm{~F}_{17} \mathrm{C}(\mathrm{O}) \mathrm{H}+\mathrm{H} 2 \mathrm{O} \rightarrow \mathrm{C}_{8} \mathrm{~F}_{17} \mathrm{CHOHOH}$ & $1.0 \times 10^{-23}\left(\mathrm{~cm}^{3} \mathrm{~s}^{-1}\right)$ & & $\mathrm{a}$ \\
\hline (25) $\mathrm{C}_{8} \mathrm{~F}_{17} \mathrm{CHOHOH}+\mathrm{OH} \rightarrow \mathrm{C}_{8} \mathrm{~F}_{17} \mathrm{C}(\mathrm{O}) \mathrm{OH}$ & $1.22 \times 10^{-13}\left(\mathrm{~cm}^{3} \mathrm{~s}^{-1}\right)$ & $0.26 \times 10^{-13}$ & $\mathrm{a}$ \\
\hline (26) $\mathrm{C}_{8} \mathrm{~F}_{17} \mathrm{CHOHOH}+\mathrm{Cl} \rightarrow \mathrm{C}_{8} \mathrm{~F}_{17} \mathrm{C}(\mathrm{O}) \mathrm{OH}$ & $5.84 \times 10^{-13}\left(\mathrm{~cm}^{3} \mathrm{~s}^{-1}\right)$ & $0.92 \times 10^{-13}$ & $\mathrm{a}$ \\
\hline (27) $\mathrm{C}_{8} \mathrm{~F}_{17} \mathrm{C}(\mathrm{O}) \mathrm{OO}+\mathrm{NO}_{2} \rightarrow \mathrm{C}_{8} \mathrm{~F}_{17} \mathrm{C}(\mathrm{O}) \mathrm{OONO}_{2}$ & $1.1 \times 10^{-11}(298 . / T)\left(\mathrm{cm}^{3} \mathrm{~s}^{-1}\right)$ & $0.1 \times 10^{-11}$ & $\mathrm{c}$ \\
\hline (28) $\mathrm{C}_{8} \mathrm{~F}_{17} \mathrm{C}(\mathrm{O}) \mathrm{OONO}_{2} \rightarrow \mathrm{C}_{8} \mathrm{~F}_{17} \mathrm{C}(\mathrm{O}) \mathrm{OO}$ & $2.8 \times 10^{16} \exp (T /-13580)\left(\mathrm{s}^{-1}\right)$ & $0.2 \times 10^{16}$ & c \\
\hline (29) $\mathrm{C}_{8} \mathrm{~F}_{17} \mathrm{C}(\mathrm{O}) \mathrm{OO}+\mathrm{NO} \rightarrow \mathrm{C}_{8} \mathrm{~F}_{17} \mathrm{OO}$ & $8.1 \times 10^{-12} \exp (T / 270)\left(\mathrm{cm}^{3} \mathrm{~s}^{-1}\right)$ & $0.6 \times 10^{-12}$ & c \\
\hline (30) $\mathrm{C}_{8} \mathrm{~F}_{17} \mathrm{C}(\mathrm{O}) \mathrm{OO}+\mathrm{HO}_{2} \rightarrow \mathrm{C}_{8} \mathrm{~F}_{17} \mathrm{C}(\mathrm{O}) \mathrm{OH}$ & $3.1 \times 10^{-13} \exp (T / 1040)\left(\mathrm{cm}^{3} \mathrm{~s}^{-1}\right)$ & $0.4 \times 10^{-13}$ & $\mathrm{c}, \mathrm{a}$ \\
\hline (31) $\mathrm{C}_{8} \mathrm{~F}_{17} \mathrm{C}(\mathrm{O}) \mathrm{OO}+\mathrm{HO}_{2} \rightarrow \mathrm{C}_{8} \mathrm{~F}_{17} \mathrm{OO}$ & $1.2 \times 10^{-13} \exp (T / 1040)\left(\mathrm{cm}^{3} \mathrm{~s}^{-1}\right)$ & $0.4 \times 10^{-13}$ & $\mathrm{c}, \mathrm{a}$ \\
\hline (32) $\mathrm{C}_{8} \mathrm{~F}_{17} \mathrm{C}(\mathrm{O}) \mathrm{OO}+\mathrm{CH}_{3} \mathrm{O}_{2} \rightarrow \mathrm{C}_{8} \mathrm{~F}_{17} \mathrm{OO}$ & $1.8 \times 10^{-12} \exp (T / 500)\left(\mathrm{cm}^{3} \mathrm{~s}^{-1}\right)$ & $3.6 \times 10^{-13}$ & $\mathrm{~b}$ \\
\hline (33) $\mathrm{C}_{8} \mathrm{~F}_{17} \mathrm{C}(\mathrm{O}) \mathrm{OO}+\mathrm{CH}_{3} \mathrm{O}_{2} \rightarrow \mathrm{C}_{8} \mathrm{~F}_{17} \mathrm{C}(\mathrm{O}) \mathrm{OH}$ & $2.0 \times 10^{-13} \exp (T / 500)\left(\mathrm{cm}^{3} \mathrm{~s}^{-1}\right)$ & 4. $\times 10^{-14}$ & $\mathrm{~b}$ \\
\hline (34) $\mathrm{C}_{8} \mathrm{~F}_{17} \mathrm{OO}+\mathrm{NO} \rightarrow \mathrm{C}_{8} \mathrm{~F}_{17} \mathrm{O}$ & $2.8 \times 10^{-12} \exp (T / 300).\left(\mathrm{cm}^{3} \mathrm{~s}^{-1}\right)$ & $1.4 \times 10^{-13}$ & $\mathrm{c}$ \\
\hline (35) $\mathrm{C}_{8} \mathrm{~F}_{17} \mathrm{OO}+\mathrm{HO}_{2} \rightarrow \mathrm{C}_{8} \mathrm{~F}_{17} \mathrm{O}$ & $4.1 \times 10^{-13} \exp (T / 500).\left(\mathrm{cm}^{3} \mathrm{~s}^{-1}\right)$ & $0.4 \times 10^{-13}$ & $\mathrm{~d}$ \\
\hline (36) $\mathrm{C}_{8} \mathrm{~F}_{17} \mathrm{OO}+\mathrm{CH}_{3} \mathrm{O}_{2} \rightarrow \mathrm{C}_{8} \mathrm{~F}_{17} \mathrm{O}$ & $2.7 \times 10^{-12} \exp (T /-470).\left(\mathrm{cm}^{3} \mathrm{~s}^{-1}\right)$ & $1.9 \times 10^{-13}$ & $\mathrm{c}$ \\
\hline (37) $\mathrm{C}_{8} \mathrm{~F}_{17} \mathrm{OO}+\mathrm{CH}_{3} \mathrm{O}_{2} \rightarrow \mathrm{C}_{8} \mathrm{~F}_{17} \mathrm{OH}$ & $1.0 \times 10^{-13} \exp (T / 660)\left(\mathrm{cm}^{3} \mathrm{~s}^{-1}\right)$ & $0.6 \times 10^{-14}$ & $\mathrm{c}$ \\
\hline (38) $\mathrm{C}_{7} \mathrm{~F}_{15} \mathrm{C}(\mathrm{O}) \mathrm{F}+\mathrm{H}_{2} \mathrm{O}(\mathrm{l}) \rightarrow \mathrm{C}_{7} \mathrm{~F}_{15} \mathrm{C}(\mathrm{O}) \mathrm{OH}$ & $3.86 \times 10^{-6}\left(\mathrm{~cm}^{3} \mathrm{~s}^{-1}\right)$ & $0.7 \times 10^{-6}$ & a \\
\hline
\end{tabular}

${ }^{a}$ Young and Mabury (2010). ${ }^{b}$ Data Evaluation (2015) using hydrocarbon analog. ${ }^{c}$ Wallington et al. (2006). ${ }^{d}$ Yarwood et al. (2007). 
Competing interests. The authors declare that they have no conflict of interest.

Acknowledgements. This work was supported by the US National Science Foundation Arctic Natural Sciences Program (1203526) and a fellowship from the National Science and Engineering Research Council of Canada (to C.P.T.).

Edited by: J. Roberts

Reviewed by: three anonymous referees

\section{References}

Bey, I., Jacob, D. J., Yantosca, R. M., Logan, J. A., Field, B., Fiore, A. M., Li, Q., Liu, H., Mickley, L. J., and Schultz, M.: Global modeling of tropospheric chemistry with assimilated meteorology: Model description and evaluation, J. Geophys. Res., 106, 23073-23096, 2001.

Butt, C. M., Young, C. J., Mabury, S. A., Hurley, M. D., and Wallington, T. J.: Atmospheric chemistry of $4: 2$ fluorotelomer acrylate $\left(\mathrm{C}_{4} \mathrm{~F}_{9} \mathrm{CH}_{2} \mathrm{CH}_{2} \mathrm{OC}(\mathrm{O}) \mathrm{CH}=\mathrm{CH}_{2}\right)$ : kinetics, mechanisms and products of chlorine atom and $\mathrm{OH}$ radical initiated oxidation, J. Phys. Chem. A, 113, 3155-3161, 2009.

Cheng, H. and Sandu, A.: Uncertainty quantification and apportionment in air quality models using the polynomial chaos method, Environ. Model. Softw., 24, 917-925, 2009.

Chiappero, M. S., Malanca, F. E., Arguello, G. A., Wooldridge, S. T., Hurley, M. D., Ball, J. C., Wallington, T. J., Waterland, R. L., and Buck, R. C.: Atmospheric chemistry of perfluoroaldehydes $\left(\mathrm{C}_{x} \mathrm{~F}_{2 x+1} \mathrm{CHO}\right)$ and fluorotelomer aldehydes $\left(\mathrm{C}_{x} \mathrm{~F}_{2 x+1} \mathrm{CH}_{2} \mathrm{CHO}\right)$ : Quantification of the important role of photolysis, J. Phys. Chem. A, 110, 11944-11953, 2006.

Conder, J. M., Hoke, R. A., de Wolf, W., Russell, M. H., and Buck, R. C.: Are PFCAs bioaccumulative? A critical review and comparison with regulatory criteria and persistent lipophilic compounds, Environ. Sci. Technol., 42, 995-1003, 2008.

Ellis, D. A., Martin, J. W., Mabury, S. A., Hurley, M. D., Andersen, M. P. S., and Wallington, T. J.: Atmospheric lifetime of fluorotelomer alcohols, Environ. Sci. Technol., 37, 3816-3820, 2003.

Ester, M., Kriegel, H.-P., Sander, J., and Xu, X.: A density-based algorithm for discovering clusters in large spatial databases with noise, 226-231, AAAI Press, Portland, Oregon, 1996.

Data Evaluation: Chemical Kinetics and Photochemical Data for Use in Atmospheric Studies, JPL Publication No. 15-10, Jet Propulsion Laboratory, California Institute of Technology, Pasadena California, available at: https://jpldataeval.jpl.nasa. gov/ (last access: November 2015), 2015.

Goss, K. U.: The pKa values of PFOA and other highly fluorinated carboxylic acids, Environ. Sci. Technol., 42, 456-458, 2008.

Houde, M., Martin, J. W., Letcher, R. J., Solomon, K. R., and Muir, D. C. G.: Biological monitoring of polyfluoroalkyl substances: a review, Environ. Sci. Technol., 40, 3463-3473, 2006.

Lucas, D. D. and Prinn, R. G.: Parametric sensitivity and uncertainty analysis of dimethylsulfide oxidation in the clear-sky remote marine boundary layer, Atmos. Chem. Phys., 5, 15051525, doi:10.5194/acp-5-1505-2005, 2005.
Martin, J. W., Mabury, S. A., Solomon, K. R., and Muir, D. C. G.: Dietary accumulations of perfluorinated acids in juvenile rainbow trout, Environ. Toxicol. Chem., 22, 189-195, 2003a.

Martin, J. W., Mabury, S. A., Solomon, K. R., and Muir, D. C. G.: Bioconcentration and tissue distribution of perfluorinated acids in rainbow trout, Environ. Toxicol. Chem., 22, 196-204, $2003 \mathrm{~b}$.

Phenix, B. D., Dinaro, J. L., Tatang, M. A., Tester, J. W., Howard, J. B., and McRae, G. J.: Incorporation of parametric uncertainty into complex kinetic mechanisms: Application to hydrogen oxidation in supercritical water, Combust. Flame, 112, 132-146, 1998.

Russell, G.: Monthly latutude insolation, available at: http://data. giss.nasa.gov/ar5/srmonlat.html, last access: November 2015.

Schenker, U., Scheringer, M., and Hungerbuhler, K.: Including degradation products of persistent organic pollutants in a global multi-media box model, Environ. Sci. Pollut. Res., 14, 145-152, 2007.

Scott, B. F., Spencer, C., Mabury, S. A., and Muir, D. C. G.: Polyand perfluorinated carboxylates in North American precipitation, Environ. Sci. Technol., 40, 7167-7174, 2006.

Seinfeld, J. H. and Pandis, S. N.: Atmospheric Chemistry and Physics: From Air Pollution to Climate Change, Wiley, Hoboken, New Jersey, 2006.

Shoeib, M., Harner, T., and Vlahos, P.: Perfluorinated chemicals in the Arctic atmosphere, Environ. Sci. Technol., 40, 7577-7583, 2006.

Stock, N. L., Furdui, V. I., Muir, D. C. G., and Mabury, S. A.: Perfluoroalkyl contaminants in the canadian Arctic: Evidence of atmospheric transport and local contamination, Environ. Sci. Technol., 41, 3529-3536, 2007.

Tatang, M. A., Pan, W., Prinn, R. G., and McRae, G. J.: An efficient method for parametric uncertainty analysis of numerical geophysical models, J. Geophys. Res., 102, 21925-21932, 1997.

Thackray, C. P.: Data and code from manuscript acp-2016-679, available at: https://github.com/thackray/pfca_precursors_data_ acp, last access: April 2017.

Thackray, C. P., Friedman, C. L., Zhang, Y., and Selin, N. E.: Quantitative Assessment of Parametric Uncertainty in Northern Hemisphere PAH Concentrations, Environ. Sci. Technol., 49, 9185 9193, 2015.

Vierke, L., Staude, C., Biegel-Engler, A., Drost, W., and Schulte, C.: Perfluorooctanoic acid (PFOA) - main concerns and regulatory developments in Europe from an environmental point of view, Environmental Sciences Europe, 24, 1-11, doi:10.1186/21904715-24-16, 2012.

Wallington, T. J., Hurley, M. D., Xia, J., Wuebbles, D. J., Sillman, S., Ito, A., Penner, J. E., Ellis, D. A., Martin, J., Mabury, S. A., Nielsen, O. J., and Andersen, M. P. S.: Formation of $\mathrm{C}_{7} \mathrm{~F}_{15} \mathrm{COOH}$ (PFOA) and other perfluorocarboxylic acids during the atmospheric oxidation of $8: 2$ fluorotelomer alcohol, Environ. Sci. Technol., 40, 924-930, 2006.

Wang, Z., Cousins, I. T., Scheringer, M., Buck, R. C., and Hungerbuhler, K.: Global emission inventories for $\mathrm{C}_{4}-\mathrm{C}_{14}$ perfluoroalkyl carboxylic acid (PFCA) homologues from 1951 to 2030, Part I: production and emissions from quantifiable sources, Environ. Int., 70, 62-75, 2014a.

Wang, Z., Cousins, I. T., Scheringer, M., Buck, R. C., and Hungerbuhler, K.: Global emission inventories for $\mathrm{C}_{4}-\mathrm{C}_{14}$ perfluoroalkyl carboxylic acid (PFCA) homologues from 1951 to 2030, 
Part II: The remaining pieces of the puzzle, Environ. Int., 69, 166-176, 2014b.

Wania, F.: A global mass balance analysis of the source of perfluorocarboxylic acids in the Arctic ocean, Environ. Sci. Technol., 41, 4529-4535, 2007.

Waterland, R. L. and Dobbs, K. D.: Atmospheric chemistry of linear perfluorinated aldehydes: Dissociation kinetics of $\mathrm{C}_{n} \mathrm{~F}_{2 n+1} \mathrm{CO}$ radicals, J. Phys. Chem. A, 111, 2555-2562, 2007.

Xie, Z., Wang, Z., Mi, W., Moller, A., Wolschke, H., and Ebinghaus, R.: Neutral Poly-/perfluoroalkyl substances in air and snow from the Arctic, Scientific Reports, 5, 226-231, 2015.

Yarwood, G., Kemball-Cook, S., Keinath, M., Waterland, R. L., Korzeniowski, S. H., Buck, R. C., Russell, M. H., and Washburn, S. T.: High-resolution atmospheric modeling of fluorotelomer alcohols and perfluorocarboxylic acids in the North American troposphere, Environ. Sci. Technol., 41, 5756-5762, 2007.
Young, C. J. and Mabury, S. A.: Atmospheric Perfluorinated Acid Precursors: Chemistry, Occurrence, and Impacts, Rev. Environ. Contam. T., 208, 1-109, 2010.

Young, C. J., Furdui, V. I., Franklin, J., Koerner, R. M., Muir, D. C. G., and Mabury, S. A.: Perfluorinated acids in Arctic snow: New evidence for atmospheric formation, Environ. Sci. Technol., 41, 3455-3461, 2007

Young, C. J., Hurley, M. D., Wallington, T. J., and Mabury, S. A.: Atmospheric chemistry of $4: 2$ fluorotelomer iodide ( $n$ $\mathrm{C}_{4} \mathrm{~F}_{9} \mathrm{CH}_{2} \mathrm{CH}_{2} \mathrm{I}$ ): kinetics and products of photolysis and reaction with $\mathrm{OH}$ radicals and $\mathrm{Cl}$ atoms, J. Phys. Chem. A, 112, 13542-13548, 2008. 